\title{
Sociodemographic Trends in National Ambulatory Care Visits for Hepatitis C Virus Infection
}

\author{
Judith I. Tsui · Judith Maselli $\cdot$ Ralph Gonzales
}

Received: 10 September 2008/ Accepted: 28 November 2008/Published online: 23 December 2008

(C) The Author(s) 2008. This article is published with open access at Springerlink.com

\begin{abstract}
Poor and non-white patients are disproportionately infected with the hepatitis $\mathrm{C}$ virus (HCV). The objective of this research is to determine sociodemographic patterns of HCV-related ambulatory care visits over time. Data from the National Ambulatory Medical Care Survey (NAMCS) and the National Hospital Ambulatory Medical Care Survey-Outpatient (NHAMCS-OPD) for the years 1997-2005 were analyzed in 3-year intervals. Demographic and other variables were compared for each period, and multivariable logistic regression was performed to examine whether the likelihood of a visit being HCVrelated (versus non-HCV) was independently associated with (1) race and/or (2) Medicaid status over time. The total number of HCV-related ambulatory visits more than doubled from 3,583,585 during the years 1997-1999 to 8,027,166 during 2003-2005. During this time, the proportion of non-whites and Medicaid recipients presenting for HCV-related visits approximately doubled (non-whites: $16 \%$ vs. $33 \%, P=0.04$; Medicaid recipients: $10 \%$ vs. $25 \%, P=0.07)$. In 2003-2005, HCV-related visits were more than twice as likely to occur among non-white patients vs. white patients (OR $=2.49$; 95\% CI: 1.60 3.86) and patients on Medicaid vs. non-Medicaid (3.49;
\end{abstract}

\section{J. I. Tsui $(\bowtie)$}

Division of General Internal Medicine, Department of Medicine, Boston University School of Medicine/Boston Medical Center, 801 Massachusetts Ave, 2nd floor, Boston, MA 02118, USA

e-mail: judith.tsui@bmc.org

J. Maselli

Department of Biostatistics, University of California,

San Francisco, USA

R. Gonzales

Division of General Internal Medicine, Department of Medicine, University of California, San Francisco, CA, USA
1.79-6.80). Our results show that HCV-associated ambulatory care visits are increasing, with a greater proportion of visits occurring among non-white patients and Medicaid recipients.

Keywords Hepatitis C . Health disparities . Ambulatory care $\cdot$ Health services

\section{Introduction}

More than 3 million Americans are now estimated to be infected with the hepatitis $\mathrm{C}$ virus (HCV) [1]. The incidence of $\mathrm{HCV}$ peaked in the 1980s (prior to blood product screening) and is now relatively low except among certain high-risk groups such as injection drug users $[2,3]$ As a consequence, most affected individuals are 40-50 years of age and have likely been infected for decades. Over time, these individuals are at risk for developing cirrhosis and liver cancer, which has prompted concern about a potential surge in $\mathrm{HCV}$-associated morbidity and mortality in the coming years [4]. Providing ambulatory care for HCVinfected individuals so that they can be evaluated for treatment should be of paramount importance.

To date, there is little information on the patterns of ambulatory health care usage among HCV-infected persons. The prevalence of HCV is disproportionately higher among minorities, illicit drug users, and individuals of low socioeconomic status [1]. These are vulnerable populations that may face numerous barriers to adequate health care. Although HCV-related healthcare utilization has been reported to be increasing overall $[5,6]$, it is unclear whether these vulnerable groups are receiving care for their HCV. This study was conducted to analyze whether the national pattern of HCV-related ambulatory care visits 
differed by age, gender, race, and insurance status over time, and to examine the proportion of visits that involved a prescription for anti-HCV therapy.

\section{Methods}

\section{Data Sources and Study Design}

Data from the National Ambulatory Medical Care Survey (NAMCS) and the National Hospital Ambulatory Medical Care Survey-Outpatient (NHAMCS-OPD) for years 19972005 were utilized. These surveys, conducted annually by the National Center for Health Statistics and the Centers for Disease Control, capture nationally representative samples of visits to ambulatory clinics (NAMCS) and hospitalbased clinics (NHAMCS-OPD). A detailed description of NAMCS and NHAMCS methodology is available through the National Center for Health Statistics [7]. In brief, trained interviewers provide materials and instruction to physicians, who then record information on patient visits during the reporting period. This study included information only on adult visits (age 18 years or older). Because of relatively small numbers of $\mathrm{HCV}$-associated visits, we combined annual survey data in 3-year intervals (19971999, 2000-2002, and 2003-2005). Analysis of this publicly available data set was exempted from institutional review board review by the University of California, San Francisco.

\section{Variables}

An HCV-related visit was defined as one in which any of the three principal diagnosis fields contained the following International Classification of Diseases, Ninth Revision (ICD-9 codes): 070.41, 070.44, 070.51, 070.54, 070.70, 070.71, or V02.62. Demographic covariates that were examined included age, sex, race (white vs. non-white), and insurance status (private, Medicare, Medicaid, or other). Additional covariates examined were whether or not the visit was conducted with the patient's primary care provider (as determined by the provider), whether the visit also contained a diagnosis code for complications from $\mathrm{HCV}$ defined as cirrhosis, ascites, esophageal varices or hepatocellular cancer (ICD-9 codes: 571.5, 571.6, 155.0, $789.5,456.1,456.2$, or 571.2), and whether the visit involved prescription of anti-HCV medications (standard and pegylated interferon alpha- $2 a$ and $2 b$, and/or ribavirin).

\section{Analyses}

All analyses took into account the complex survey design using weights, strata, and primary sampling unit design variables when calculating estimates. Comparisons of the proportion of visits representing certain patient demographics and prescription of anti-HCV therapy for each 3year interval were compared using a Chi-square test. Multivariable logistic regression was performed to examine whether the likelihood of a visit being HCV-related (versus unrelated to HCV) was independently associated with race and Medicaid status, and whether there was an interaction between time and those covariates (i.e., whether the effects of race and Medicaid status varied over time). A $P$-value threshold of $<0.05$ was used for all statistical testing, including tests for interaction. All analyses were conducted using SAS version 9.1.3 (SAS Institute, Cary, NC) and SUDAAN, version 9.0.3 (RTI International, Research Triangle Park, NC).

\section{Results}

Using this data source, it is estimated that national HCVrelated ambulatory visits increased from 3,583,585 (95\% CI: $2,305,477$ to $4,861,693)$ during $1997-1999$ to $8,027,166(3,714,378$ to $12,339,954)$ during $2003-2005$ (Fig. 1). These weighted estimates were based on an absolute number of 276 visits, 468 visits, and 583 visits for the years 1997-1999, 2000-2002, and 2003-2005, respectively (estimates are not stable for fewer than 30 visits) [7]. HCV-related visits constituted a larger percentage of total ambulatory visits over time: they comprised $0.17 \%$ of total visits in $1997-1999,0.26 \%$ in 2000-2002, and $0.33 \%$ in 2003-2005 (Chi-square $P$ value $=0.04 ;$ trend $P$-value $=0.1$ )

Over the time period examined, the proportion of nonwhites and Medicaid recipients presenting for $\mathrm{HCV}$-related visits approximately doubled (Table 1). A relatively small number of visits involved a prescription for anti-HCV medications $(<10 \%)$, and the proportion did not appear to be changing over time. Likewise, a minority of HCVrelated visits also involved complications such as cirrhosis

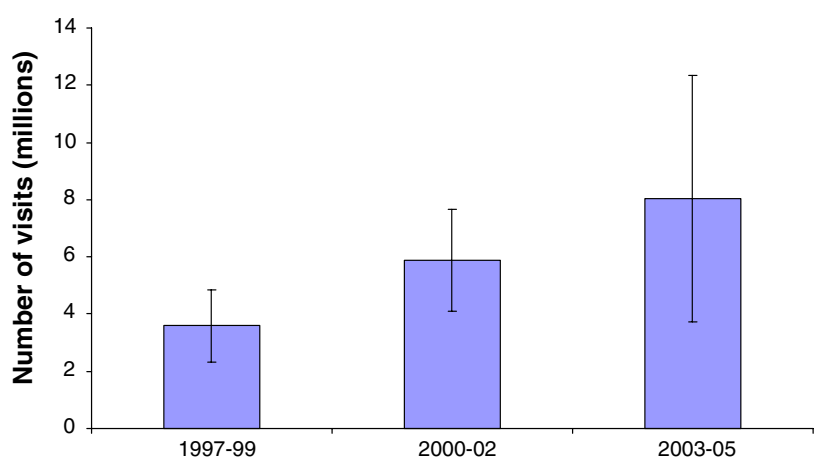

Fig. 1 Estimated number of HCV-related ambulatory visits in the U.S. 
Table 1 Characteristics of HCV-related ambulatory visits (NAMCS/NHAMCS-OPD combined)

\begin{tabular}{|c|c|c|c|c|}
\hline & $\begin{array}{l}1997-1999 \\
N=3,583,585 \\
N(\%)\end{array}$ & $\begin{array}{l}2000-2002 \\
N=5,875,678 \\
N(\%)\end{array}$ & $\begin{array}{l}2003-2005 \\
N=8,027,166 \\
N(\%)\end{array}$ & $P$-value \\
\hline \multicolumn{5}{|l|}{ Gender } \\
\hline Female & $1,594,071(44)$ & $2,020,134(34)$ & $2,702,298(34)$ & \multirow[t]{2}{*}{0.46} \\
\hline Male & $1,989,514(56)$ & $3,855,544(66)$ & $5,324,868(66)$ & \\
\hline \multicolumn{5}{|l|}{ Age } \\
\hline $18-39$ & $841,005(23)$ & $1,210,659(21)$ & $1,184,421(15)$ & \multirow[t]{3}{*}{0.83} \\
\hline $40-59$ & $2,302,117(64)$ & $3,775,097(64)$ & $5,459,966(68)$ & \\
\hline$\geq 60$ & $440,463(12)$ & $889,922(15)$ & $1,382,779(17)$ & \\
\hline \multicolumn{5}{|l|}{ Race } \\
\hline White & $3,015,711(84)$ & $4,708,309(80)$ & $5,339,075(67)$ & \multirow[t]{2}{*}{0.04} \\
\hline Non-white & $567,874(16)$ & $1,167,369(20)$ & $2,688,091(33)$ & \\
\hline \multicolumn{5}{|l|}{ Insurance } \\
\hline Private & $2,169,151(60)$ & $3,029,322(52)$ & $3,993,254(50)$ & \multirow[t]{4}{*}{0.21} \\
\hline Medicare & $655,850(18)$ & $773,304(13)$ & $911,405(11)$ & \\
\hline Medicaid & $342,788(10)$ & $1,048,284(18)$ & $2,015,782(25)$ & \\
\hline Other $^{\mathrm{a}}$ & $415,796(12)$ & $1,024,768(17)$ & $1,106,725(14)$ & \\
\hline Medicaid (vs. non-Medicaid) & $342,788(10)$ & $1,048,284(18)$ & $2,015,782(25)$ & 0.07 \\
\hline Diagnosis of $\mathrm{HCV}$ complications ${ }^{\mathrm{b}}$ & $199,785(6)^{\mathrm{c}}$ & $314,129(5)$ & $508,510(6)$ & 0.92 \\
\hline Prescription of anti-HCV meds & $247,138(7)^{\mathrm{c}}$ & $565,892(9.6)$ & $503,428(6.3)$ & 0.76 \\
\hline Primary care provider visit ${ }^{\mathrm{d}}$ & $1,502,684(45)$ & $2,400,056(43)$ & $3,466,357(45)$ & 0.97 \\
\hline
\end{tabular}

and liver cancer, and there was no appreciable change over time. Almost half of all HCV-related visits occurred with the patient's primary care provider.

Results from the logistic regression, adjusting for age and sex, demonstrated that HCV-related visits were more likely to occur among non-whites and recipients of Medicaid over time (time-race interaction $P$-value $=0.02$; time-Medicaid interaction $=0.04$ ). In the most recent years (2003-2005), HCV-related visits were more than twice as likely to occur among non-white patients, and more than three times as likely to occur among patients on Medicaid (Table 2).

Table 2 Relative odds for visit being HCV-related (vs. non-HCV) associated with race and Medicaid status*

\begin{tabular}{llll}
\hline Covariate & $1997-1999$ & $2000-2002$ & $2003-2005$ \\
\hline White & Ref & Ref & Ref \\
Non-white & $1.04(0.58,1.87)$ & $1.43(0.87,2.34)$ & $2.49(1.60,3.86)$ \\
$\begin{array}{c}\text { Non- } \\
\quad \text { Medicaid }\end{array}$ & Ref & Ref & Ref \\
Medicaid & $1.49(0.80,2.80)$ & $3.54(2.44,5.14)$ & $3.49(1.79,6.80)$ \\
\hline
\end{tabular}

* Results from the logistic regression were adjusted for age and sex

\section{Conclusions}

This study suggests that the number of HCV-related ambulatory care visits in the U.S. is rising, with an increasing percentage of visits occurring among non-white patients and recipients of Medicaid. Additionally, we observed that only a small percentage $(<10 \%)$ of ambulatory HCV-related visits involved anti-HCV treatment, and that the proportion of visits involving treatment did not increase between 1997 and 2005.

There are some potential explanations for our finding that an increasing proportion of HCV-related ambulatory visits occurred among non-whites and Medicaid recipients. First, this may reflect the positive efforts to screen and bring to care individuals who are infected with HCV. National guidelines for HCV screening do not target any particular race or socioeconomic group [8], however, the prevalence of $\mathrm{HCV}$ is substantially higher among minorities and individuals of low socioeconomic status. Increasing proportions may reflect greater numbers of individuals from these vulnerable groups who become aware of their diagnosis and are able to access health care. As the incidence of acute $\mathrm{HCV}$ is extremely low ( 0.3 per 
100,000) [3], it seems unlikely that a differential rate of new infections among non-whites and Medicaid recipients can fully explain our findings. Another possibility is that a differential rate of $\mathrm{HCV}$-associated complications among whites and non-whites compels individuals to seek out care, as some prior research has suggested disparities between whites and blacks in liver disease outcomes [9]; however, the relatively small number of visits involving $\mathrm{HCV}$-associated complications observed appears to argue against this being a major driving force behind our findings.

Regardless of cause, our findings have important public health implications. The findings support prior research showing an increasing contribution of HCV to national healthcare expenditures $[5,6]$, but add to the literature by showing that Medicaid is increasingly shouldering the costs of ambulatory healthcare for HCV. Politicians and policymakers should be aware of the potential for increased Medicaid ambulatory care costs due to HCV. Further, if HCV-related complications such as cirrhosis and liver cancer (and costly treatments like liver transplant) increase in the future, as some researchers have predicted [4], there may be a substantial burden to the public healthcare system. It is nonetheless interesting to note that in this study the proportion of $\mathrm{HCV}$-related ambulatory visits that were associated with complications did not increase over the study period. Models predicting $\mathrm{HCV}$-associated burden have projected increases in HCV-related morbidity and mortality that peak around 2015 [10], so this study may have been conducted too early to detect upward trends in complications.

This study also found that only a small percentage of HCV-related ambulatory care visits $(<10 \%)$ involved prescription of anti-HCV medications by the provider. Because the data contain no patient-specific information on treatment history, candidacy, and preferences, we cannot determine to what extent this proportion falls short of treatment guidelines. However, the seemingly low percentage of observed visits that involved treatment appears congruent with prior research showing substantial contraindications and barriers to treatment for many HCV-positive patients $[11,12]$. In this study, almost half of the HCVrelated visits occurred with a self-identified "primary care provider." If a significant proportion of HCV care is taking place in the offices of non-specialist primary care providers, training non-specialist providers to treat $\mathrm{HCV}$ may be one strategy to provide greater access to treatment for patients.

This study has several important limitations. Because the study is based on a sample of visits, rather than individuals, observations are restricted to the level of health care utilization. There was potential for misclassification, in particular not identifying all visits that involved HCV- related care. Because the survey only allowed for three diagnosis codes, patients with HCV who had multiple comorbidities may have not have had their visit coded to reflect their $\mathrm{HCV}$ care. Finally, we had relatively small absolute numbers of HCV-related visits and even fewer visits that involved treatment; therefore we were unable to examine patterns of treatment among subgroups, such as non-whites and Medicaid recipients.

In summary, using a nationally representative survey, we found that HCV-related ambulatory care visits are increasing, and that more visits are occurring among nonwhite and Medicaid patients over time. Since the current incidence of $\mathrm{HCV}$ is low, this may reflect improved efforts to provide care for poor, non-white individuals who are chronically infected with HCV. Policy-makers should be aware that HCV-related ambulatory care visits are increasingly paid through Medicaid insurance, which may place a growing burden on the public health care system in the future.

Acknowledgments Dr. Tsui's efforts were supported by grant number KL2RR024130 from the NCRR, a component of NIH. The authors do not report any conflicts of interest.

Open Access This article is distributed under the terms of the Creative Commons Attribution Noncommercial License which permits any noncommercial use, distribution, and reproduction in any medium, provided the original author(s) and source are credited.

\section{References}

1. Armstrong GL, Wasley A, Simard EP, McQuillan GM, Kuhnert WL, Alter MJ. The prevalence of hepatitis $C$ virus infection in the United States, 1999 through 2002. Ann Intern Med. 2006;144(10): 705-714.

2. Alter MJ. Epidemiology of hepatitis C. Hepatology. 1997;26 Suppl 1(3):62S-65S. doi:10.1002/hep.510260711.

3. Wasley A, Grytdal S, Gallagher K. Surveillance for acute viral hepatitis-United States, 2006. MMWR Surveill Summ. 2008; 57(2):1-24

4. Armstrong GL, Alter MJ, McQuillan GM, Margolis HS. The past incidence of hepatitis $\mathrm{C}$ virus infection: implications for the future burden of chronic liver disease in the United States. Hepatology. 2000;31(3):777-782. doi:10.1002/hep.510310332.

5. Grant WC, Jhaveri RR, McHutchison JG, Schulman KA, Kauf TL. Trends in health care resource use for hepatitis $C$ virus infection in the United States. Hepatology. 2005;42(6): 1406-1413. doi:10.1002/hep.20941.

6. Kim WR. The burden of hepatitis $\mathrm{C}$ in the United States. Hepatology. 2002;36 Suppl 1(5):S30-S34. doi:10.1053/jhep. 2002.36791.

7. http://www.cdc.gov/nchs/about/major/ahcd/ahcd1.htm.

8. Recommendations for prevention and control of hepatitis $\mathrm{C}$ virus (HCV) infection and HCV-related chronic disease. Centers for Disease Control and Prevention. MMWR Recomm Rep. 1998; 47(RR-19):1-39.

9. Nguyen GC, Thuluvath PJ. Racial disparity in liver disease: biological, cultural, or socioeconomic factors. Hepatology. 2008;47(3):1058-1066. doi:10.1002/hep.22223. 
10. Wong JB, McQuillan GM, McHutchison JG, Poynard T. Estimating future hepatitis $\mathrm{C}$ morbidity, mortality, and costs in the United States. Am J Public Health. 2000;90(10):1562-1569.

11. Mehta SH, Thomas DL, Sulkowski MS, Safaein M, Vlahov D, Strathdee SA. A framework for understanding factors that affect access and utilization of treatment for hepatitis $\mathrm{C}$ virus infection among HCV-mono-infected and HIV/HCV-co-infected injection drug users. AIDS. 2005;19(Suppl 3):S179-S189. doi:10.1097/01. aids.0000192088.72055.90.

12. Bini EJ, Brau N, Currie S, et al. Prospective multicenter study of eligibility for antiviral therapy among 4,084 U.S. veterans with chronic hepatitis C virus infection. Am J Gastroenterol. 2005; 100(8):1772-1779. doi:10.1111/j.1572-0241.2005.41860.x. 